\title{
The Temporal and Contextual Stability of Activity Levels in
}

\section{Hippocampal CA1 Cells}

Yuichiro Hayashi $^{1 *}$, Ko Kobayakawa ${ }^{1}$, and Reiko Kobayakawa ${ }^{1}$

${ }^{1}$ Institute of Biomedical Sciences, Kansai Medical University, 2-5-1 Shin-machi,

Hirakata, Osaka 573-1010, Japan

*Correspondence: hayasyui@hirakata.kmu.ac.jp 


\section{Abstract}

Recent studies have shown that the activity levels of hippocampal neurons during exploration are not constant but change on a daily to weekly scale. However, a few other studies suggest that their activity levels are preserved over time. To resolve this contradiction, we repeatedly measured the neural activity of the mouse hippocampus in four different environments. The activity level of hippocampal neurons fluctuated greatly in one environment, but the mean activity level across all the environments was more stable. Each cell's preferred environment frequently changed over time. The number of environments in which a cell showed activity varied across cells, ranging from zero to four, and the value also tended to be preserved. Cells that showed place cell activity in many environments had higher mean firing rates and higher spatial information content, whereas cells active only in a small number of environments were suitable for coding environmental identity. These results suggest that although the activity level in a single environment appears unstable, each cell has not only an inherent activity level but also play a characteristic role in the coding of space.

\section{Keywords}

Hippocampus, CA1, place cell, calcium imaging 


\section{Introduction}

The hippocampus is known as a brain region that plays a crucial role in episodic

memory formation. To support this, the activity of hippocampal neurons has been found

to encode place, environment, time, and various task-relevant information (Ferbinteanu

and Shapiro, 2003; MacDonald et al., 2011; Muller and Kubie, 1987; O'Keefe and

Dostrovsky, 1971; Pastalkova et al., 2008; Wood et al., 2000). In particular, place cell

activity, i.e., the activity of hippocampal cells in restricted portions in an environment,

has been extensively studied (Moser et al., 2015; O'Keefe and Nadel, 1978). The

activity pattern of place cells can change or disappear when animals move to a different

environment (Alme et al., 2014; Lu et al., 2015; Muller and Kubie, 1987; O'Keefe and

Conway, 1978). This phenomenon is called remapping, and it seems to provide a

mechanism through which the hippocampus represents different environments.

To store episodic information in a neural circuit, the activity must reliably

respond to the same external stimuli across long timescales. However, recent studies

have shown that the place receptive fields and activity levels of hippocampal neurons

are not constant, but fluctuate on a daily to weekly scale (Cai et al., 2016; Gonzalez et

al., 2019; Hayashi, 2019; Kinsky et al., 2018; Rubin et al., 2015; Ziv et al., 2013). Such

fluctuations are called "representational drift" and have also been found in other brain 
regions, such as the parietal cortex, visual cortex, and olfactory cortex (Deitch et al.,

2021; Driscoll et al., 2017; Schoonover et al., 2021). On the contrary, several studies

have reported evidence that each cell has a preconfigured activity level and that the

firing rates of the neurons in the hippocampus and entorhinal cortex are preserved

across different brain states (Hirase et al., 2001; Mizuseki and Buzsáki, 2013).

Recording in a very large environment ( $>40 \mathrm{~m}$ long) revealed that the location of the

place fields of hippocampal neurons fluctuated on the day to week timescale, but the

number of place fields was preserved over months (Lee et al., 2020).

One possible explanation for this discrepancy is that the former studies were

recorded in small spaces $\left(<1 \mathrm{~m}^{2}\right)$, while the latter was measured in a large environment.

In a larger environment, a greater number of cells show place cell activity and the size

and number of place field for each cell increase (Fenton et al., 2008; Rich et al., 2014).

Considering the presence of representational drift in the place fields, their activity levels

appear to fluctuate in a small environment, but not in a large environment if the size is

enough to average out the fluctuations. If that is the case, the averaged activity for

multiple small environments should be preserved over time.

In the present study, we measured neural activity in the mouse hippocampal

CA1 area in four different environments with different sizes and colors over time. The 
activity level of hippocampal neurons fluctuated greatly in one environment but was

stable when averaged across all environments. We also found that the number of

environments in which the cells showed activity also tended to be conserved.

\section{Results}

\section{Experimental outline}

To investigate the place cell activity for multiple spatial environments in the

hippocampus, neural activity was recorded successively in four arenas with different

shapes and colors (Figure 1A). Before commencing the recording sessions, mice $(n=6)$

were trained to chase food in these arenas for at least five days. Each mouse then

underwent four 5-min recording sessions per day for three-day intervals (Figure 1A).

Neural activity in the dorsal CA1 region of the hippocampus was recorded

using a combination of a genetically encoded calcium indicator GCaMP6f and a

miniature microscope (Figure 1B and C). We extracted calcium traces of putative

neurons from the fluorescence image stream using CNMF-E (Zhou et al., 2018). The

firing rate of each neuron was estimated from its calcium trace using OASIS software

(Pnevmatikakis et al., 2016) (Figure 1D). The firing rate distribution of the recorded

cells showed lognormal distribution (Figure 1E), which was consistent with the findings 
of the previous electrophysiological study (Mizuseki and Buzsáki, 2013).

\section{Activity of CA1 cells showed a variety of environmental specificity}

A total of 6425 cells were recorded from six mice in four different environments. In accordance with a previous study, we found a variety of cells ranging from those that showed no activity in any environment to those that showed activity in all the four environments (Figure 2A and B) (Lu et al., 2015). We termed the number of environments where a cell exhibited activity above the threshold as the "global activity level index" (gA index). Because a fraction of cells in the hippocampus show activity but are not place cells, we also classified cells according to the number of environments where a cell showed statistically significant PC activity. The value was termed "global place cell activity level index" (gPC index). As shown in Figure 2C, CA1 cells showed a variety of gPC activity levels. The fraction of place cell did not change between environments or over days, indicating that these mice were highly familiar to all the environments (Figure S1).

\section{Activity level averaged across multiple environments was more stable than that for}

\section{a single environment}


We analyzed the stability of neural activity of each cell in a single environment and across all four environments. To make a fair comparison, the mean firing rate for four environments was calculated over 5-min of data randomly extracted from recordings in the four environments. We plotted the relationship between the activity levels of two consecutive sessions with an interval of three days. As show in Figure 3A, the activity correlation for each single environment was lower than that for the averaged activity across all environments. To quantify the activity correlation, we calculated the firing rate difference, which refers to the absolute values of differences between mean firing rates divided by their sum. A significantly higher correlation was observed for the averaged activity across all environments than for an activity in a single environment (Figure 3B $U=3.73 \times 10^{9}, p=2.02 \times 10^{5}, \mathrm{n}=77100$ observations of cells for single environment, $\mathrm{n}=19275$ observations of cells for all environments, Mann-Whitney $U$ test). The fluctuating activity for single environment and stable averaged activity across multiple environments (Figure 3A) suggested that each cell changed preference for its environment. To test this, the environment in which each cell showed the highest firing rate across all environments was visualized. As shown in Figure 3C, each cell's preferred environment (highest firing rate environment) changed frequently across sessions, and the transition rate of the preferred environment was $\sim 0.6$ (Figure 3D). 


\section{The gA and gPC indexes were preserved over time}

Next, we tested whether the gA and gPC indexes were preserved. A significant

correlation of the gA index between adjacent sessions was found (Figure 4A, n $=90$

session pairs, $\mathrm{r}=0.780, p<0.0001)$. We used a threshold value of $0.01 \mathrm{~Hz}$, but a

significant correlation was also found with threshold levels ranging from 0.01 to 0.08

$\mathrm{Hz}$ (Figure S2). The gPC index between adjacent sessions was also correlated (Figure

4B, $\mathrm{n}=90$ session pairs, $\mathrm{r}=0.724, p<0.0001)$. These results indicate that not the only

mean firing rate but also the $\mathrm{gA} / \mathrm{gPC}$ index of each cell tended to be preserved over

time.

Given that each cell has a preserved activity level and gA/gPC index, we

wanted to determine whether cells have inherent roles. We then investigated the

relationship between $\mathrm{gA} / \mathrm{gPC}$ index and the cells' firing properties. The cells showing

higher gPC index had a higher mean firing rates and spatial information rates (Figure

5A, mean firing rate: $\mathrm{H}_{(4,25545)}=390.8, p<0.0001, \mathrm{n}=8516$ observations of neurons

over all recording sessions; 5B, spatial information: $\mathrm{H}_{(3,25545)}=427.4, p<0.0001, \mathrm{n}=$

8516 observations of place cells over all recording sessions, Kruskal-Wallis test

followed by Dunn's post hoc test). However, the spatial information content per spike 
was not significantly different among the groups (Figure $5 \mathrm{C}, \mathrm{H}_{(3,25545)}=78.73, p<$

$0.0001, \mathrm{n}=8516$ observations of place cells over all recording sessions, Kruskal-Wallis

test followed by Dunn's post hoc test). Therefore, the higher information rate by cells

showing gPC index was attributed to their higher firing rates. These results indicate that

high firing rate and high gPC index cells convey an animal's precise location

information.

On the other hand, cells active in only a few environments can sparsely and

efficiently code environmental identity. To test this, we calculated firing rate differences

between the firing rate for the environment where a cell showed the highest firing rate

and firing rate averaged over the other three environments. Cells do not necessarily

possess position information when encoding the environment. Therefore, we classified

cells with the gA index. The firing rate difference between the maximum firing

rate-environment and the others was highest with the gA index $=1$ (Figure $5 \mathrm{D}, \mathrm{H}_{(3,36933)}$

$=724.3, p<0.0001, \mathrm{n}=12312$ observations of cells over all recording sessions,

Kruskal-Wallis test followed by Dunn's post hoc test). This indicates that cells with a

low gA index code the environmental identity rather than the animal's location. 


\section{Discussion}

In this study, using the head-mount miniature fluorescence microscope, we measured

the neural activity of hippocampal CA1 cells over time in four different environments

(Figure 1). There are contrasting reports on the long-term stability of the activity of

CA1 cells. It has been shown that the place field location and activity levels of CA1

cells are not constant but fluctuate on a daily to weekly scale (Cai et al., 2016; Gonzalez

et al., 2019; Hayashi, 2019; Kinsky et al., 2018, 2020; Rubin et al., 2015; Ziv et al.,

2013). In contradiction to these observations, a recent study reported that the activity

levels of CA1 cells in a very large ( 40 m long) environment were stable over time,

though the location of their place field fluctuated (Lee et al., 2020). The results of this

study can resolve this contradiction. In agreement with former studies, we showed that

the activity level of each CA1 cell in a small environment $\left(\sim 0.1 \mathrm{~m}^{2}\right)$ varied over days

(Figure 3A, Left). However, the temporal variation in the averaged activity level across

four environments was smaller (Figure 3A, Right). Previous studies have shown that in

a small $\left(\sim 0.4 \mathrm{~m}^{2}\right)$ environment, the number of place field of each cell is typically one,

whereas in larger environment, the number of place field for each cell increases (Fenton

et al., 2008; Rich et al., 2014). Therefore, it is possible that the activity level in a large

environment is more stable than in a small environment if the size of the environment is 
enough to average out the activity fluctuation due to representational drift. The activity levels for multiple environments are also more stable than that for single environment due to the presence of representational drift.

We also showed the gA and gPC indexes tended to be preserved over time (Figure 4A and B). This suggests that CA1 cells play an inherent role in spatial coding. Cells that show activity only in a small number of environments (small gA index) sparsely and efficiently code environmental identity (Figure 5D), whereas cells that show PC activity in many environments convey rich information of the location in any environment. Notably, both $\mathrm{gA}$ and $\mathrm{gPC}$ indexes are not binary, but are gradually distributed (Figure 2B and C). Therefore, the possible roles of CA1 cells in spatial coding are also gradual; there are cells with diverse size of spatial receptive fields from a portion of an environment to multiple environments.

One of the questions to be addressed next is the relationship between gPC activity level and c-Fos expression. In the present study, we recorded neural activity in a familiar environment, but not during a new experience (Figure 1). In contrast to exploration in familiar environment, exposure to a novel environment or learning a new task induces an immediate early gene c-Fos in a subset of hippocampal cells, and the artificial activation of these cells induces memory recall (Liu et al., 2012). Therefore, 
these cells are considered to be involved in a specific memory. Moreover, a recent study

reported that c-Fos expressing place cells in the CA1 have distinct firing properties.

Place cells expressing c-Fos during novel experiences showed higher mean firing rates

and less spatial information content from those c-Fos negative cells. Interestingly, the

c-Fos positive cells also showed a spatial environment-selective firing pattern but the

c-Fos negative cells did not (Tanaka et al., 2018). The relationship between c-Fos

expression and $\mathrm{gA} / \mathrm{gPC}$ index during learning is a topic for future research.

\section{Acknowledgments}

This work is supported by JSPS KAKENHI (Grant No. 17K19436, 20K07715) to Y.H.,

JSPS KAKENHI 20H04849 to R.K.

\section{Author Contributions}

Conceptualization, Y.H.; Methodology, Y.H.; Investigation, Y.H.; Writing -Original

Draft, Y.H.; Writing -Review \& Editing, Y.H., K.K. and R.K.; Funding Acquisition, Y.H.

and R.K.; Resources, Y.H., K.K. and R.K.; Supervision, Y.H. 


\section{Figure Legends}

\section{Figure 1. Experimental overview.}

(A) Mice explored four testing arenas per day for three-day intervals. (B) Left, Section

diagram of the miniature microscope. Right, Schematic representation of the objective

lens and the chronic window implant above CA1. (C) Maximum intensity projection of

the fluorescence image stream. (D) Upper, an example calcium trace of a cell. Lower,

spike train estimated with OASIS software. (E) Distribution of the firing rates of CA1

cells $(\mathrm{n}=6425$ cells $)$. Histogram: data; red line: lognormal fit.

\section{Figure 2. Hippocampal activity recorded in the four environments}

Place cell activity in four different environments. (A) Top row, top view of the four

environments. Second row. typical mouse's trajectories. From third to bottom rows.

Place field maps for five representative cells. Red indicates the maximum firing rate and

blue indicates silent. Regions not visited by the mouse are shown in gray. Asterisks

represent activity above threshold (mean firing rate $>0.01 \mathrm{~Hz}$ ). (B) Distribution of gA

index with variable threshold for activity. Data represent mean \pm SEM $(n=24$ sessions

from six mice). (C) Distribution of gPC index. Data represent mean \pm SEM ( $n=24$ 
sessions from six mice).

\section{Figure 3. Session-to-session activity dynamics in multiple environments}

(A) Change of firing rate between two adjacent sessions. Each dot shows one cell's firing rates across two adjacent sessions. Left, firing rates in a single (same)

environment. Right, averaged firing rates over all four environments. (B) Firing rate difference between two adjacent sessions. The box plots show the median and quartiles, and the whisker caps of the box plots show the minimum and maximum values.

Asterisks indicate significant differences $(* * * P<0.0001)$. (C) Change of environmental selectivity. Environments in which each cell exhibits the highest firing rate in each session are displayed. (D) Transition rates of environmental selectivity across adjacent sessions. Each dot shows an individual animal. Solid lines indicate mean value.

\section{Figure 4. Session-to-session dynamics of gA/gPC index}

(A) Changes in cell's gA index between two adjacent sessions. Left, data are shown as mean \pm SEM ( $\mathrm{n}=18$ session pairs from six animals). Right, open circles represent each value. The solid line shows a linear regression fit to the data. (B) Changes in cell's gPC index between two adjacent sessions. Left, data are shown as mean \pm SEM ( $n=18$ 
session pairs from six animals). Right, open circles represent each value. The solid line shows a linear regression fit to the data. Asterisks indicate significant correlation $(* * * P$ $<0.0001)$.

\section{Figure 5. Relationship between $\mathrm{gA} / \mathrm{gPC}$ index and cell's firing properties}

(A) gPC index versus mean firing rates. (B) gPC index versus spatial information rates.

(C) gPC index versus spatial information rate per spike. (D) gA index versus firing rate difference between the firing rate for the environment in which a cell showed the highest firing rate and firing rate averaged over the other three environments. The box plots show the median and quartiles, and the whisker caps of the box plots show the minimum and maximum values. Asterisks indicate significant differences $(* * * P<$ $0.0001)$.

\section{Meterial and Methods}

\section{Experimental model and subject details}

\section{Animal subjects}

All experiments complied with the applicable guidelines and regulations. Animal care 
and use followed protocols approved by the Animal Research Committee of Kansai

Medical University. All experiments complied with the ARRIVE guidelines

(https://arriveguidelines.org/arrive-guidelines/experimental-animals). Nine adult male

C57BL/6N mice aged 12-18 weeks were used. The mice were purchased from Japan

SLC, Inc. (Shizuoka, Japan), housed under a standard 12-h light/dark cycle, and allowed

ad libitum access to food and water.

\section{Viral constructs}

We obtained an AAVrh10.hSyn.GCaMP6f.WPRE.SV40 virus from the University of

Pennsylvania Vector Core at a titer of $\sim 1.3 \times 10^{14} \mathrm{GC} / \mathrm{mL}$ and diluted it to $\sim 5 \times 10^{12}$

GC/mL with phosphate buffered saline.

\section{Miniature head-mount microscope}

The miniature microscope design was based on the UCLA miniscope v3

(miniscope.org). Excitation light was emitted by a blue LED (LXML-PB01-0030;

Lumileds, Aachen, Germany). The light passed through an excitation filter (ET470/40x;

Chroma Technology, Bellows Falls, VT) and was reflected by a dichroic mirror

(T495lpxr; Chroma Technology) onto the tissue through an EWTL (Varioptic A-25H0; 
Corning, Corning, NY), an objective lens (tandem configuration of achromatic doublets;

\#84-126 and \#49-271, Edmund Optics, Burlington, NJ). The fluorescent emissions

collected by the lenses were passed through the dichroic mirror and an emission filter

(ET525/50m; Chroma Technology). The fluorescence image was focused by a tube lens

(\#49-277; Edmund Optics) and captured by a CMOS image sensor (MT9V032; ON

Semiconductor, Phoenix, AZ). The microscope body was made using a 3D printer

(From2, resin type FGPBLK03; Formlabs, Somerville, MA). The design files are

available at https://github.com/yuichirohayashi/Zscope. The driving voltage for the

EWTL (square wave, $2 \mathrm{kHz}$ ) was generated using a data acquisition board (PCIe-6259,

National Instruments, Dallas, TX) controlled by custom software written in LABVIEW

7.1 (National Instruments, Dallas, TX) and amplified with a linear amplifier

(As-904-150B, NF Corporation, Yokohama, Japan).

\section{Method Details}

\section{Surgery}

The animals were anesthetized using isoflurane. The skull was exposed, and a small

hole $(<0.5 \mathrm{~mm})$ was made over the right hemisphere ( $1.5 \mathrm{~mm}$ lateral to the midline, 2.3

$\mathrm{mm}$ posterior to the bregma). Then, $200 \mathrm{~nL}$ of GCaMP6f virus was injected into CA1 
(1.2 $\mathrm{mm}$ ventral from the brain surface). One week after the viral injection, the animals

were anesthetized using isoflurane, and a $2.8 \mathrm{~mm}$-diameter craniotomy was performed.

The dura was removed, and the underlying cortex was aspirated. A stainless-steel

cannula (2.76 mm outer diameter, $2.40 \mathrm{~mm}$ inner diameter, $1.5 \mathrm{~mm}$ height) covered by a

glass coverslip (0.12 mm thick) was inserted over the dorsal CA1. Dental cement

(Shofu, Kyoto, Japan) was used to glue the cannula to the skull.

Four weeks after the cannula implantation, GCaMP-expressing neurons were

imaged using the head-mount microscope. The aluminum baseplate of the microscope

was cemented in a position at which the neurons were visible.

\section{Experimental Outline}

\section{Recording arenas}

Calcium activity was recorded in four arenas of different shapes and colors: a tall green

box $(37 \times 25 \times 56 \mathrm{~cm}$ high $)$, a short gray box $(37 \times 25 \times 35 \mathrm{~cm}$ high $)$, a lime round

basket $(39 \times 26 \times 25 \mathrm{~cm}$ high $)$, and a white square basket $(36 \times 25 \times 25 \mathrm{~cm} \mathrm{high})$. One

side of each arena was painted a different color or decorated with plastic tape (Figure

1A). 


\section{Behavioral training}

One week after the baseplate surgery, the mice were food-restricted and maintained at above $85 \%$ of their initial weight. Mice were trained to forage for food pellets (14 $\mathrm{mg}$, \#F05684, Bio-Serv, Flemington, NJ) scattered on the floor of the arenas.

\section{Recording sessions}

After at least five days of behavioral training, mice underwent four 5-min recording sessions per day in the four different arenas in a random sequential order. The arenas were cleaned with $70 \%$ ethanol prior to each recording session to eliminate any olfactory cues. During sessions, food pellets were thrown into the arena about every 1 min. The excitation light intensity was approximately $0.1-0.5 \mathrm{~mW} / \mathrm{mm}^{2}$, and fluorescence images were captured at $30 \mathrm{~Hz}$. The focus was adjusted to match the previous one. To record mouse behavior, an overhead camera (DMK22BUC03, The Imaging source, Bremen, Germany) was used.

\section{Quantification and Statistical Analyses}

All significance values are described in the text. Statistical analyses were performed using GraphPad Prism 5 (GraphPad Software, La Jolla, CA) and MATLAB 2019a. The 
statistical significance was set at $P<0.05$ for all statistical analyses.

\section{Image processing}

ImageJ 1.52 (National Institutes of Health, MA) and MATLAB 2019a (Mathworks,

Natick, MA) were used for all analyses. The calcium imaging data recorded at same day

were concatenated and processed using MiniscopeAnalysis

(https://github.com/etterguillaume/MiniscopeAnalysis). First, the images were

downsampled spatially by factors of two and motion-corrected using NoRMCorre

(Pnevmatikakis and Giovannucci, 2017). The downsampled, motion-corrected videos

were then processed using CNMF-E (Zhou et al., 2018) to extract fluorescence traces

from individual neurons. The fluorescence traces were finally processed using OASIS

software (Pnevmatikakis et al., 2016) for denoizing and deconvolving to estimate

spiking activity.

\section{Registration of cells across sessions}

For day-to-day longitudinal cell registration, we used Cellreg (Sheintuch et al., 2017)

and used the probabilistic model (psame threshold $=0.5$ ) based on the spatial

correlation of the identified cell masks. 


\section{Place fields}

To analyze the place fields, calcium events that occurred when the animal's velocity was

less than $1 \mathrm{~cm} / \mathrm{s}$ were filtered out to eliminate nonspecific activity at rest. The place

field maps were constructed by finding the spike number at each spatial bin $(2 \mathrm{~cm} \times 2$

$\mathrm{cm}$ ) divided by the dwell time in the bin. The maps were smoothed using a Gaussian

function with a standard deviation of $3 \mathrm{~cm}$.

For each place field of the cells, the mutual information between calcium

transients and the mouse's location was calculated (Skaggs et al., 1993). To assess the

significance of spatial selectivity, Monte Carlo $P$ values were calculated. A total of 1000

distinct shuffles of the calcium transient times were performed and the mutual

information for each shuffle was calculated. The $P$ value was defined as the fraction of

shuffles that exceeded the mutual information of the cell. Cells with $P<0.05$ were

considered place cells.

\section{Rate difference}

The rate difference in the place field was determined by calculating the unsigned rate

difference between the peak calcium transient rates in the two recording sessions and by 
dividing the difference by the sum of the two rates.

\section{References}

Alme, C.B., Miao, C., Jezek, K., Treves, A., Moser, E.I., and Moser, M.-B. (2014).

Place cells in the hippocampus: Eleven maps for eleven rooms. Proc. Natl. Acad. Sci.

$111,18428-18435$.

Cai, D.J., Aharoni, D., Shuman, T., Shobe, J., Biane, J., Song, W., Wei, B., Veshkini,

M., La-Vu, M., Lou, J., et al. (2016). A shared neural ensemble links distinct contextual

memories encoded close in time. Nature 534, 115-118.

Deitch, D., Rubin, A., and Ziv, Y. (2021). Representational drift in the mouse visual

cortex. Curr. Biol. 31, 4327-4339.

Driscoll, L.N., Pettit, N.L., Minderer, M., Chettih, S.N., and Harvey, C.D. (2017).

Dynamic Reorganization of Neuronal Activity Patterns in Parietal Cortex. Cell 170,

986-999.

Fenton, A.A., Kao, H.-Y., Neymotin, S.A., Olypher, A., Vayntrub, Y., Lytton, W.W.,

and Ludvig, N. (2008). Unmasking the CA1 Ensemble Place Code by Exposures to

Small and Large Environments: More Place Cells and Multiple, Irregularly Arranged, 
and Expanded Place Fields in the Larger Space. J. Neurosci. 28, 11250-11262.

Ferbinteanu, J., and Shapiro, M.L. (2003). Prospective and retrospective memory

coding in the hippocampus. Neuron 40, 1227-1239.

Gonzalez, W.G., Zhang, H., Harutyunyan, A., and Lois, C. (2019). Persistence of neuronal representations through time and damage in the hippocampus. Science 825 , $821-825$.

Hayashi, Y. (2019). NMDA receptor-dependent dynamics of hippocampal place cell ensembles. J. Neurosci. 39, 5173-5182.

Hirase, H., Leinekugel, X., Czurko, A., Csicsvari, J., and Buzsaki, G. (2001). Firing rates of hippocampal neurons are preserved during subsequent sleep episodes and modified by novel awake experience. Proc. Natl. Acad. Sci. 98, 9386-9390.

Kinsky, N.R., Sullivan, D.W., Mau, W., Hasselmo, M.E., and Eichenbaum, H.B. (2018).

Hippocampal Place Fields Maintain a Coherent and Flexible Map across Long

Timescales. Curr. Biol. 28, 3578-3588.

Kinsky, N.R., Mau, W., Sullivan, D.W., Levy, S.J., Ruesch, E.A., and Hasselmo, M.E. (2020). Trajectory-modulated hippocampal neurons persist throughout memory-guided navigation. Nat. Commun. 11, 1-14.

Lee, J.S., Briguglio, J.J., Cohen, J.D., Romani, S., and Lee, A.K. (2020). The Statistical 
Structure of the Hippocampal Code for Space as a Function of Time, Context, and

Value. Cell 183, 620-635.

Liu, X., Ramirez, S., Pang, P.T., Puryear, C.B., Govindarajan, A., Deisseroth, K., and Tonegawa, S. (2012). Optogenetic stimulation of a hippocampal engram activates fear memory recall. Nature $484,381-385$.

Lu, L., Igarashi, K.M., Witter, M.P., Moser, E.I., and Moser, M.B. (2015). Topography

of Place Maps along the CA3-to-CA2 Axis of the Hippocampus. Neuron 87,

1078-1092.

MacDonald, C.J., Lepage, K.Q., Eden, U.T., and Eichenbaum, H. (2011). Hippocampal

"time cells" bridge the gap in memory for discontiguous events. Neuron 71, 737-749.

Mizuseki, K., and Buzsáki, G. (2013). Preconfigured, skewed distribution of firing rates in the hippocampus and entorhinal cortex. Cell Rep. 4, 1010-1021.

Moser, M.-B., Rowland, D.C., and Moser, E.I. (2015). Place Cells, Grid Cells, and Memory. Cold Spring Harb. Perspect. Biol. 7, a021808.

Muller, R.U., and Kubie, J.L. (1987). The effects of changes in the environment on the spatial firing of hippocampal complex-spike cells. J. Neurosci. 7, 1951-1968.

O’Keefe, J., and Conway, D.H. (1978). Hippocampal place units in the freely moving rat: why they fire where they fire. Exp. Brain Res. 31, 573-590. 
O’Keefe, J., and Dostrovsky, J. (1971). The hippocampus as a spatial map. Preliminary

evidence from unit activity in the freely-moving rat. Brain Res $34,171-175$.

O’Keefe, J., and Nadel, L. (1978). The hippocampus as a cognitive map (Oxford

University Press).

Pastalkova, E., Itskov, V., Amarasingham, A., and Buzsaki, G. (2008). Internally

Generated Cell Assembly Sequences in the Rat Hippocampus. Science 321, 1322-1327.

Pnevmatikakis, E.A., and Giovannucci, A. (2017). NoRMCorre: An online algorithm

for piecewise rigid motion correction of calcium imaging data. J. Neurosci. Methods

291, 83-94.

Pnevmatikakis, E.A.A., Soudry, D., Gao, Y., Machado, T.A., Merel, J., Pfau, D.,

Reardon, T., Mu, Y., Lacefield, C., Yang, W., et al. (2016). Simultaneous Denoising,

Deconvolution, and Demixing of Calcium Imaging Data. Neuron 89, 299.

Rich, P.D., Liaw, H.P., and Lee, A.K. (2014). Large environments reveal the statistical

structure governing hippocampal representations. Science 345, 814-817.

Rubin, A., Geva, N., Sheintuch, L., and Ziv, Y. (2015). Hippocampal ensemble

dynamics timestamp events in long-term memory. Elife 4, 1-16.

Schoonover, C.E., Ohashi, S.N., Axel, R., and Fink, A.J.P. (2021). Representational

drift in primary olfactory cortex. Nature 594, 541-546. 
Sheintuch, L., Rubin, A., Brande-Eilat, N., Geva, N., Sadeh, N., Pinchasof, O., and Ziv,

Y. (2017). Tracking the Same Neurons across Multiple Days in Ca2+ Imaging Data.

Cell Rep. 21, 1102-1115.

Skaggs, W.E., McNaughton, B.L., Gothard, K.M., and Markus, E.J. (1993). An

information-theoretic approach to deciphering the hippocampal code (San Mateo, CA:

Morgan Kaufmann).

Tanaka, K.Z., He, H., Tomar, A., Niisato, K., Huang, A.J.Y., and McHugh, T.J. (2018).

The hippocampal engram maps experience but not place. Science 361, 392-397.

Wood, E.R., Dudchenko, P.A., Robitsek, R.J., and Eichenbaum, H. (2000).

Hippocampal neurons encode information about different types of memory episodes

occurring in the same location. Neuron 27, 623-633.

Zhou, P., Resendez, S.L., Rodriguez-Romaguera, J., Jimenez, J.C., Neufeld, S.Q.,

Stuber, G.D., Hen, R., Kheirbek, M.A., Sabatini, B.L., Kass, R.E., et al. (2018).

Efficient and accurate extraction of in vivo calcium signals from microendoscopic video

data. Elife 7, 1-37.

Ziv, Y., Burns, L.D., Cocker, E.D., Hamel, E.O., Ghosh, K.K., Kitch, L.J., El Gamal, A., and Schnitzer, M.J. (2013). Long-term dynamics of CA1 hippocampal place codes. Nat

Neurosci 16, 264-266. 
bioRxiv preprint doi: https://doi.org/10.1101/2022.01.24.477445; this version posted January 25, 2022. The copyright holder for this preprint (which was not certified by peer review) is the author/funder, who has granted bioRxiv a license to display the preprint in perpetuity. It is made available under aCC-BY-ND 4.0 International license. 
bioRxiv preprint doi: https://doi.org/10.1101/2022.01.24.477445; this version posted January 25, 2022. The copyright holder for this preprint (which wasiggt 6ortified by peer review) is the author/funder, who has granted bioRxiv a license to display the preprint in perpetuity. It is made available under aCC-BY-ND 4.0 International license.

A

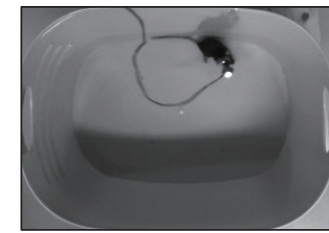

env A

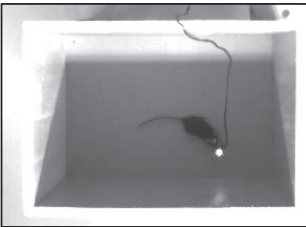

env B

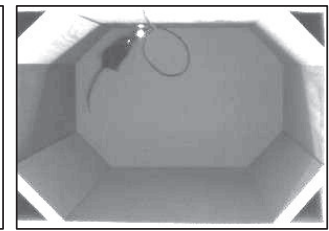

env C

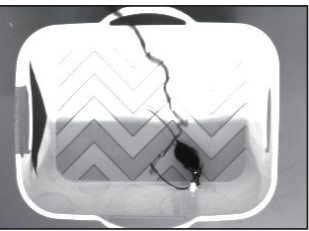

env D

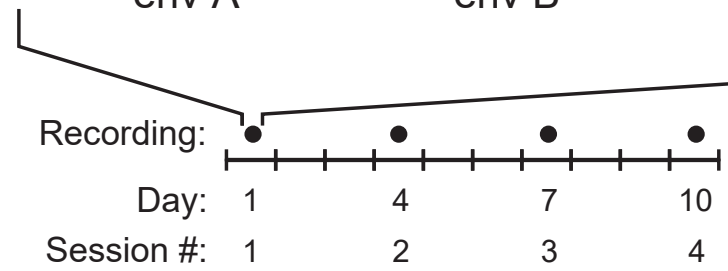

B
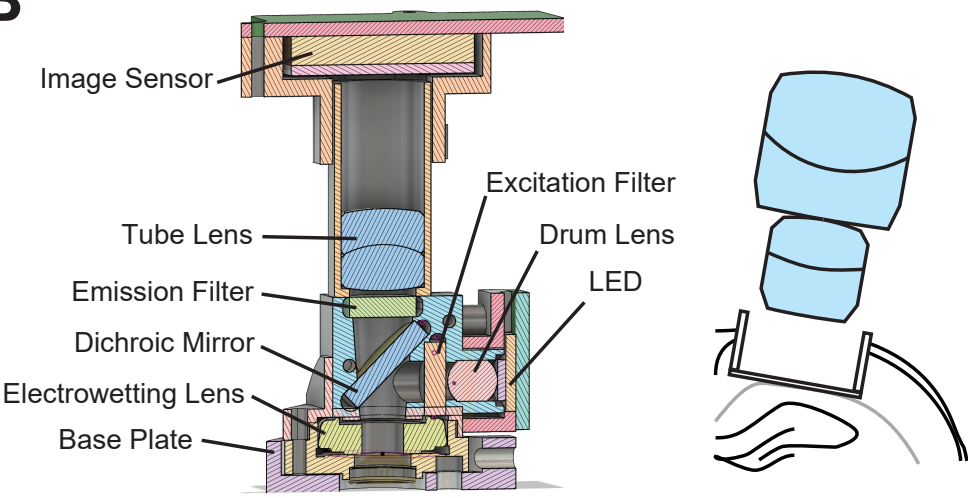

C

D
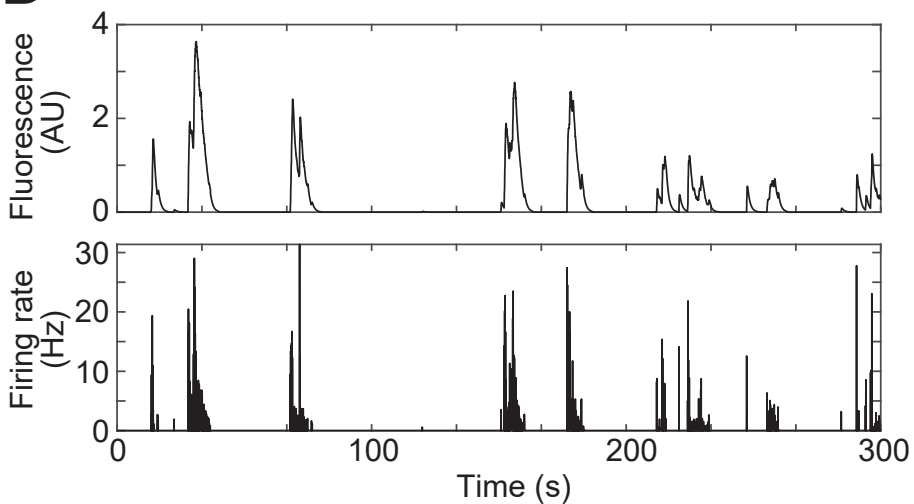

E
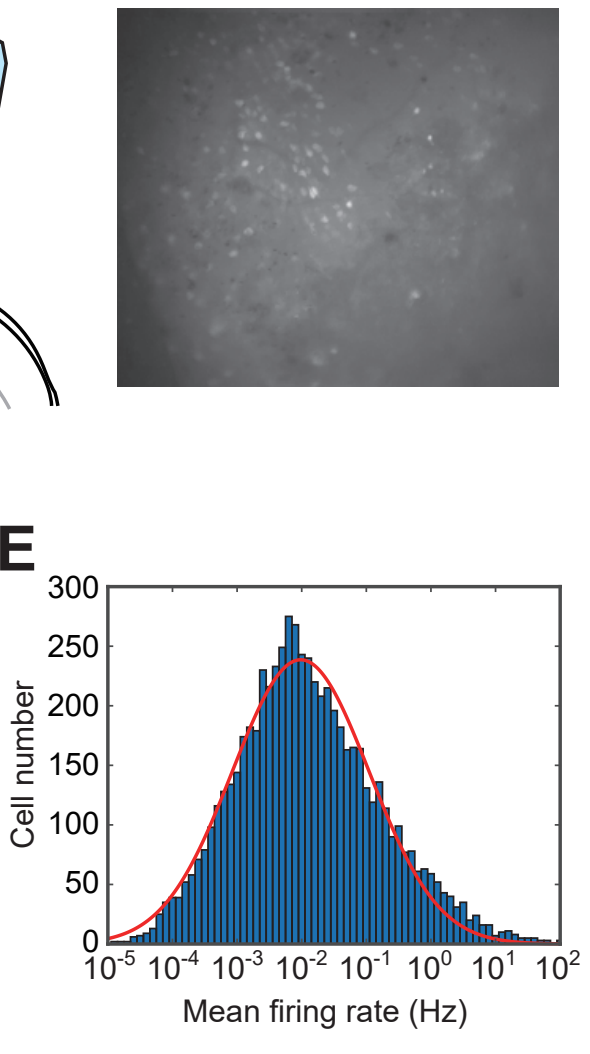
bioRxiv preprint doi: https://doi.org/10.1101/2022.01.24.477445; this version posted January 25, 2022. The copyright holder for this preprint (which was not certified by peer review) is the author/funder, who has granted bioRxiv a license to display the preprint in perpetuity. It is made Figure 2 available under aCC-BY-ND 4.0 International license.

A

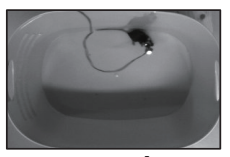

env A
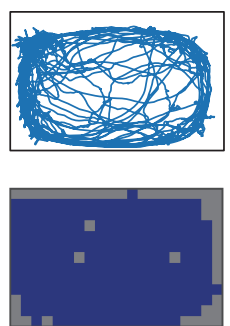

*

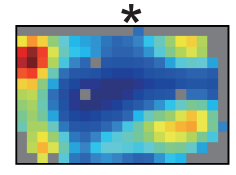

Cell ID: 11

2 env active
Cell ID: 56

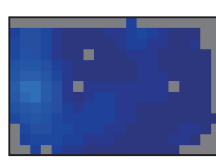

*

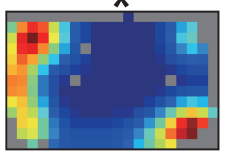

*

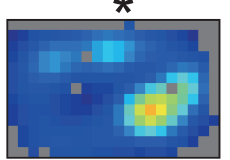

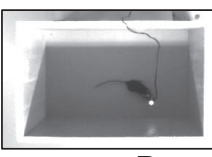

env B
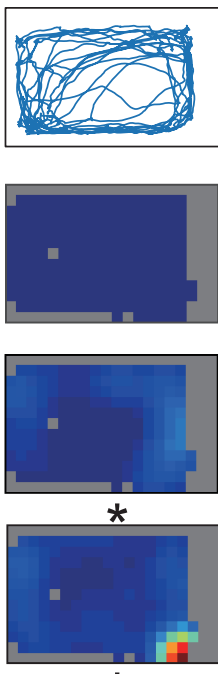

*

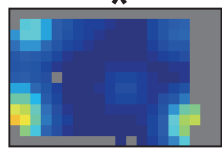

$\star$

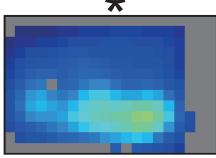

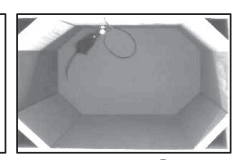

env $\mathrm{C}$

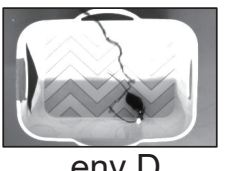

env D
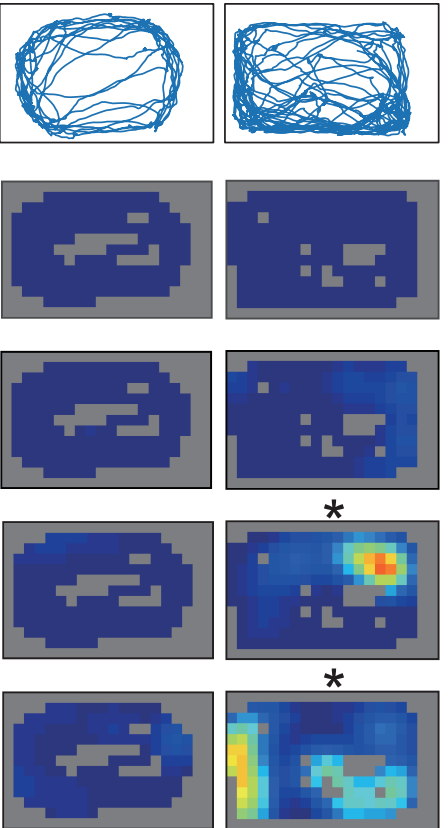

*
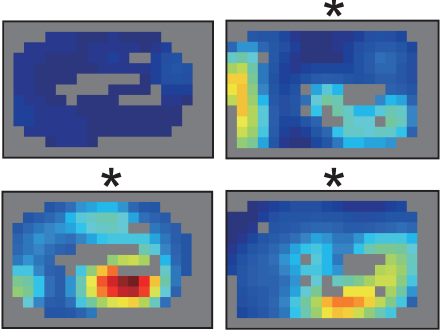

B

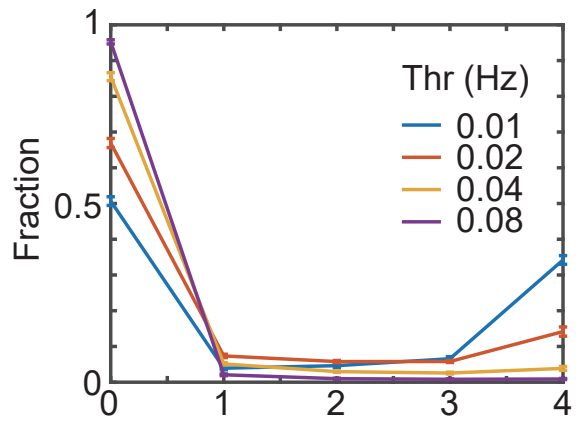

Number of active environments

(gA index)
C

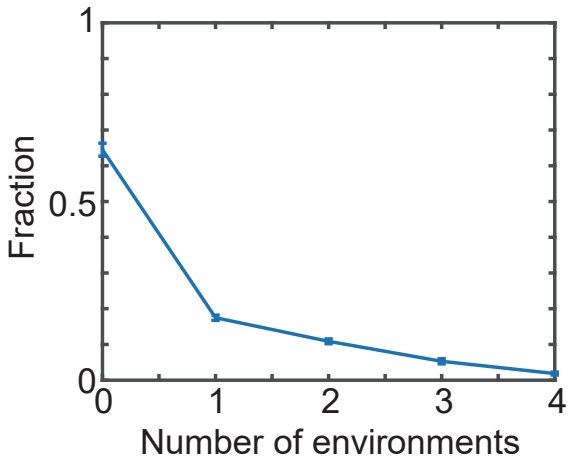

where each cell shows PC activity (gPC index) 
bioRxiv preprint doi: https://doi.org/10.1101/2022.01.24.477445; this version posted January 25, 2022. The copyright holder for this preprint (which was not Fqtifiedebyzeer review) is the author/funder, who has granted bioRxiv a license to display the preprint in perpetuity. It is made available under aCC-BY-ND 4.0 International license.

A

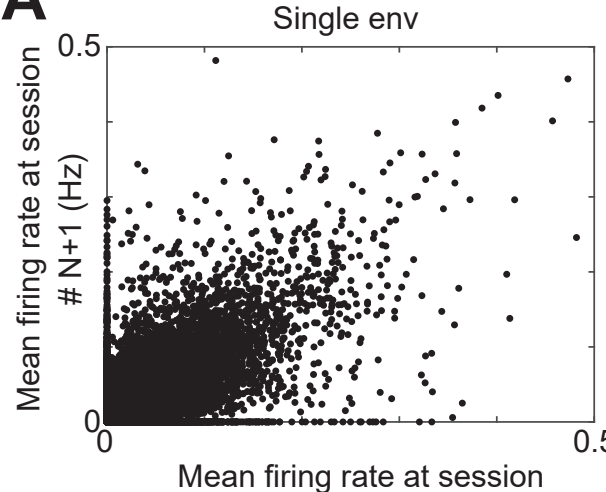

\# $\mathrm{N}(\mathrm{Hz})$
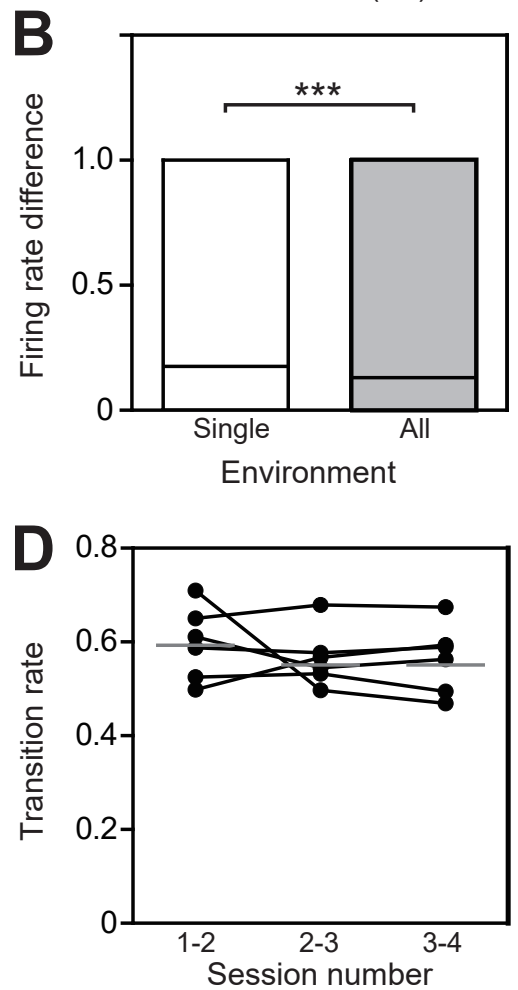

All env

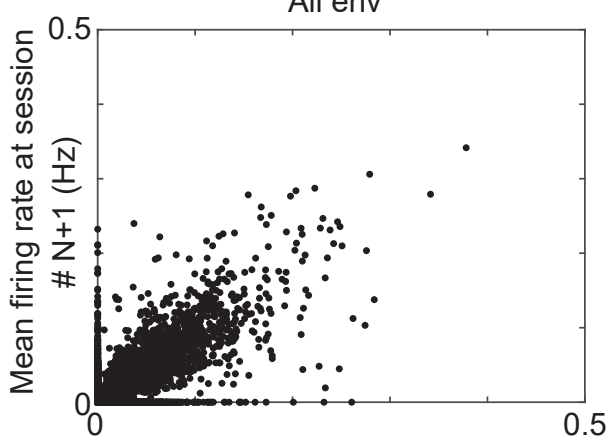

Mean firing rate at session

\# N (Hz)

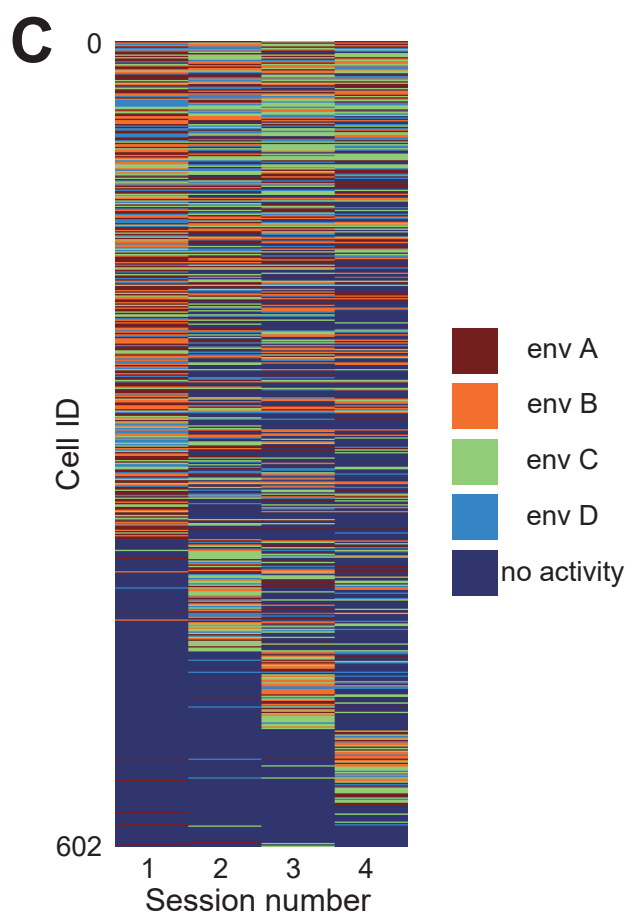


bioRxiv preprint doi: https://doi.org/10.1101/2022.01.24.477445; this version posted January 25, 2022. The copyright holder for this preprint (which was not certified by peer review) is the author/funder, who has granted bioRxiv a license to display the preprint in perpetuity. It is made available under aCC-BY-ND 4.0 International license.

Figure 4

A
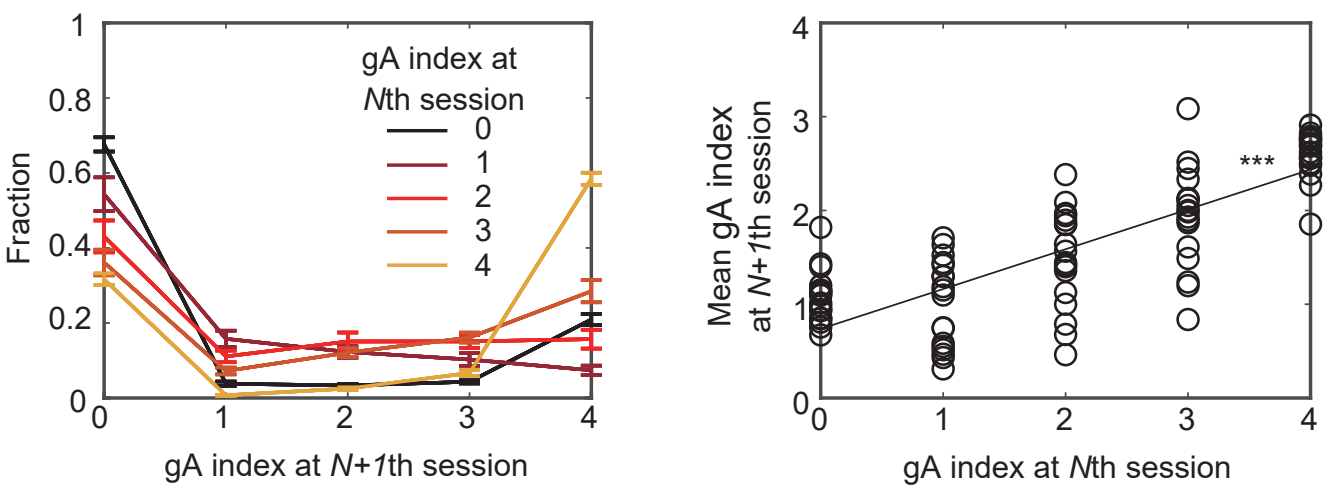

B
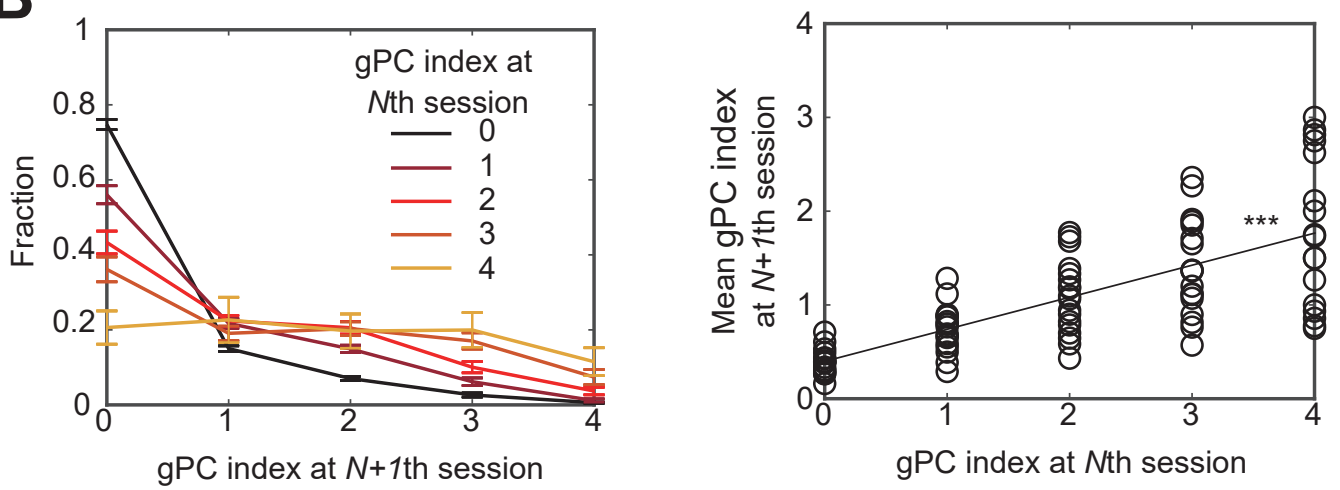
Figure 5
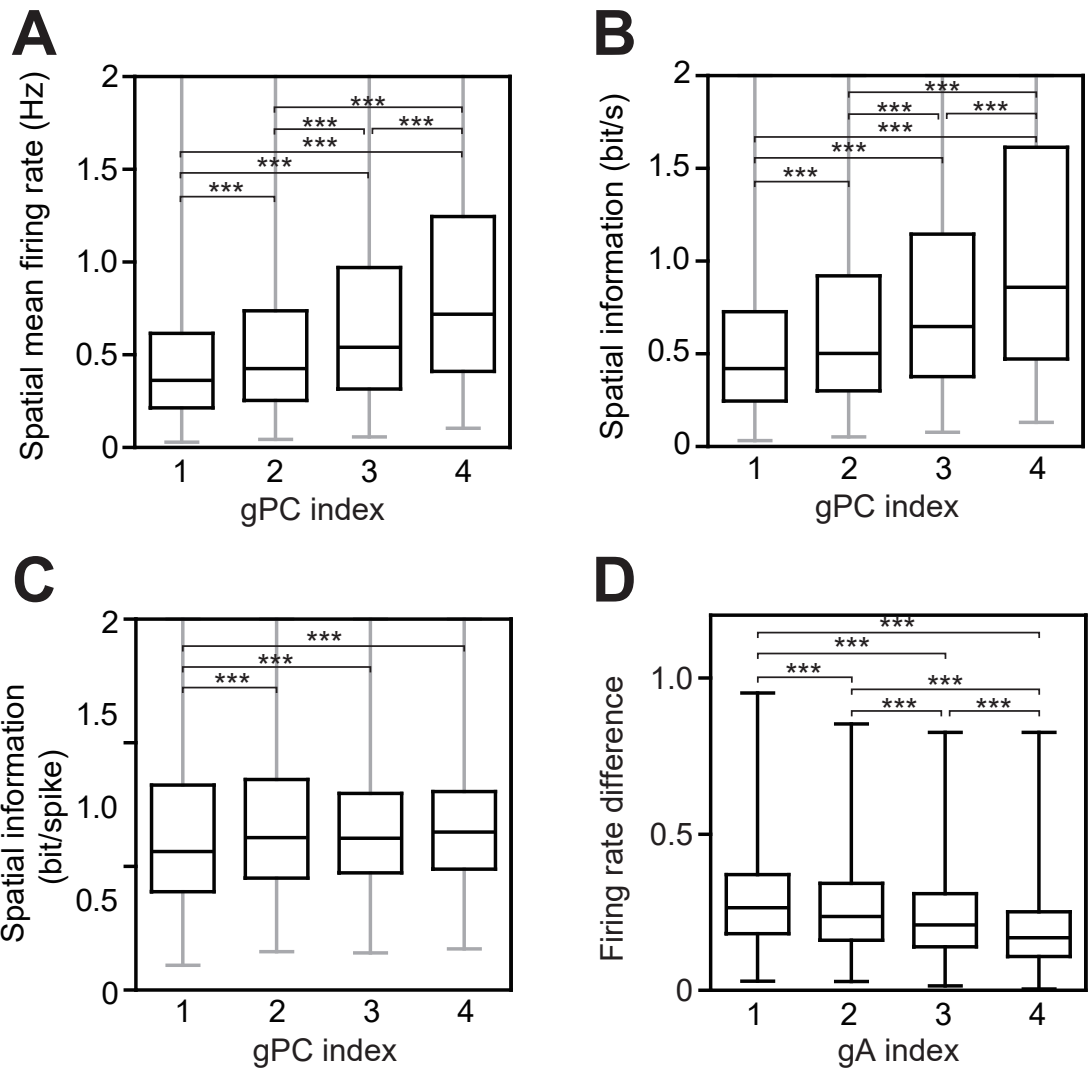